\title{
Maternal arterial stiffness in hypertensive pregnancies with and without a small-for-gestational-age neonate
}

Helen Perry ${ }^{1,2}$, Juande Gutierrez ${ }^{1}$, Julia Binder ${ }^{1,3}$, Basky Thilaganathan ${ }^{1,2}$, Asma Khaliil ${ }^{1,2}$

${ }^{1}$ Fetal Medicine Unit, St George's University Hospitals NHS Foundation Trust, Blackshaw Road, London SW17 ORE, UK

\author{
${ }^{2}$ Vascular Biology Research Centre, Molecular and Clinical Sciences Research \\ Institute, St George's University of London, London SW17 ORE, UK \\ ${ }^{3}$ Department of Obstetrics and Fetomaternal Medicine, \\ Medical University of Vienna, Austria
}

\section{Corresponding author:}

Professor Asma Khalil

Fetal Maternal Medicine Unit

St George's University of London

London SW17 ORE

E-mail: akhalil@sgul.ac.uk; asmakhalil79@googlemail.com

Keywords: Arterial stiffness, augmentation index, preeclampsia, pulse wave velocity, small for gestational age

Short title: Arterial stiffness is higher in HDP with SGA 


\section{CONTRIBUTION}

What are the novel findings of this work?

Arterial stiffness is a prognostic marker for cardiovascular disease. Women who develop HDP have higher Alx compared to normotensive controls and Alx is highest in those with an associated SGA neonate.

What are the clinical implications of this work?

Measuring Alx could help identify those most at risk of SGA and later life cardiovascular disease. 


\section{ABSTRACT}

Objective: Pregnancies complicated by preeclampsia with a small for gestational age (SGA) neonate have poorer hemodynamic function compared to women with hypertensive disorders of pregnancy (HDP) and an appropriately grown neonate. Arterial stiffness is a recognised prognostic marker of cardiovascular disease in the general population. The aim of this study was to compare arterial stiffness in hypertensive pregnancies with and without SGA fetuses.

Methods: This was a prospective case control study of hypertensive and healthy normotensive pregnancies. Arterial stiffness, as assessed by pulse wave velocity (PWV) and aortic augmentation index (Alx), was recorded using a non-invasive device (Arteriograph ${ }^{\circledR}$ ). Maternal and hemodynamic factors were adjusted for using linear regression analysis. Comparisons between groups were carried out using Mann-Whitney or Chi-Square (or Fisher's exact) test for categorical variables.

Results: Sixty-nine patients with HDP with SGA, 129 patients with HDP with a normally grown fetus and 220 healthy controls were included in the analysis. Maternal age, weight, height and heart rate were significantly associated with brachial and aortic Alx, whilst maternal weight, height, mean arterial pressure, heart rate and gestational age were significant predictors of aortic PWV. Both the HDP with SGA and HDP-only groups had significantly higher adjusted aortic Alx compared to controls $(12.5 \%$ and $10.0 \%$ vs. $7.6 \%$; both $p<0.05)$ and were significantly different to each other $(P=0.002)$.

Adjusted PWV was significantly higher in the HDP-only group compared to the control group and the HDP with SGA group $(7.7 \mathrm{~m} / \mathrm{s}$ vs. $7.1 \mathrm{~m} / \mathrm{s}$ and $7.1 \mathrm{~m} / \mathrm{s}$, both $p<0.001)$. Conversely, the unadjusted value was not significantly different between the two hypertensive groups $(p=0.414)$.

Conclusions: Pregnancies complicated by HDP with SGA or HDP-only have significantly higher aortic Alx compared to uncomplicated normotensive pregnancies. Aortic Alx was highest in those pregnancies complicated by preeclampsia with SGA, 
reflecting a progression in severity of arterial stiffness abnormality with a worsening clinical picture. These findings most likely reflect systemic reduced vascular compliance and increased systemic vascular resistance in HDP pregnancies.

\section{Introduction}

Women who have pregnancies complicated by preeclampsia and gestational hypertension are at an increased risk of both hypertension and cardiovascular disease in later life. ${ }^{1-4}$ Furthermore, the subsequent risk of developing hypertension or cardiovascular disease correlates with the severity of the preeclampsia that these women sustain. A large systematic review and meta-analysis found that the relative risk of developing ischaemic heart disease following preeclampsia is 2.17 (1.92-2.45) compared to women with normotensive pregnancies. However, for women who develop preterm preeclampsia ( $<37$ weeks), this is increased to 7.71 (4.40-13.52). ${ }^{2}$ Women who develop preterm preeclampsia also have more modifiable cardiovascular risk factors than women with term preeclampsia. ${ }^{5}$ In addition to the gestational onset of preeclampsia, the co-existence of fetal growth restriction is also a marker of disease severity. ${ }^{6,7}$ We have recently demonstrated that pregnancies complicated by preeclampsia with a small for gestational age (SGA) neonate have worse hemodynamic function than pregnancies with preeclampsia or gestational hypertension alone (under review).

Arterial stiffness is a marker of vascular health and is a prognostic marker for cardiovascular disease in the general population. ${ }^{8,9}$ Both pulse wave velocity (PWV), which is a direct measure of arterial stiffness, and augmentation index (Alx), which is a surrogate measure of arterial stiffness, can be measured non-invasively in pregnancy. We, and others, have demonstrated increased arterial stiffness before and during the clinical stage of preeclampsia. ${ }^{10-16}$ However, it is less clear if arterial stiffness differs with the varying severity of the clinical picture. If this were the case it 
would add to our understanding of the role of cardiovascular health in the development of preeclampsia. The aim of this study was therefore to investigate PWV and Alx in pregnancies complicated by hypertensive disorders of pregnancy (HDP) with and without a SGA neonate and in normotensive control pregnancies. 


\section{Methods}

\section{Study population and recruitment}

This was a prospective case control study of pregnancies complicated by preeclampsia or gestational hypertension and normotensive control pregnancies presenting to a tertiary referral hospital between January 2012 and May 2018. The inclusion criteria were singleton pregnancies with a viable fetus at 20 weeks' gestation or greater with gestational hypertension or preeclampsia, defined according to the ISSHP 2014 revised criteria: $^{17}$

- Gestational Hypertension: 'de novo hypertension ( $\geq 140 / 90 \mathrm{mmHg}$ ) after 20 weeks gestation.'

- Preeclampsia: "de novo hypertension ( $\geq 140 / 90 \mathrm{mmHg})$ after 20 weeks gestation with the coexistence of proteinuria, other maternal organ dysfunction or fetal growth restriction.'

The exclusion criteria were women with multiple pregnancies, a history of chronic hypertension or cardiac disease and pregnancies complicated by aneuploidy, genetic syndromes or major structural fetal abnormalities. A small for gestational age neonate was defined as having a birthweight below the $10^{\text {th }}$ centile. All Pregnancies were dated according to crown-rump length measurement in the first trimester in accordance with national guidelines. ${ }^{18}$ When the first ultrasound examination was performed after 14 weeks' gestation, pregnancies were dated according to head circumference measurement. ${ }^{19}$

Patients were recruited at or shortly after they were first diagnosed with hypertension in pregnancy. The majority of patients were recruited from the obstetric assessment unit, with some recruited from antenatal clinic or as inpatients. They were assigned a diagnosis as per the above criteria. Birthweight was obtained from hospital records and women with preeclampsia or gestational hypertension were divided into two groups: those who had a small for gestational age neonate (HDP with SGA) and those with an appropriately grown neonate (HDP-only). According to the modified 
ISSHP criteria, those in the SGA group had preeclampsia whilst those in the hypertension-only group had either gestational hypertension or preeclampsia. Therefore, the final diagnosis for the study was confirmed after delivery. The control group had no pre-existing cardiac or metabolic disease. Those control pregnancies that subsequently developed hypertension or resulted in the birth of a small for gestational age neonate were excluded from the analysis. Patients in the control group were recruited whilst attending a routine antenatal visit or a third trimester ultrasound assessment (placental localisation, presentation, measuring small or large for dates on fundal height measurement). Those that had an ultrasound were only included if the ultrasound demonstrated a normally grown fetus with normal liquor volume and Doppler measurements. Written consent was obtained from all study participants and research ethics committee approval (12/LO/0810) was obtained prior to performing the study investigations.

\section{Research Investigations}

All arterial stiffness measurements for this project were obtained using the Arteriograph $^{\circledR}$ device (TensioMed, Budapest, Hungary). This is a non-invasive, oscillometric arterial stiffness device that uses a brachial arm cuff to detect pressure changes in the brachial artery. The device works by first inflating the cuff to measure brachial blood pressure. It then continues to inflate to $35 \mathrm{mmHg}$ above the systolic blood pressure. By inflating to suprasystolic pressure, the cuff completely occludes the brachial artery. The energy of the arterial waveform that was travelling towards the point of occlusion is instead transmitted to the surrounding upper arm soft tissue. As this is largely composed of fluid, making it incompressible, the energy is transmitted to the skin surface. As the skin under the cuff expands with the increased pressure, the cuff is compressed. This reduction in cuff volume is converted to an increase in pressure which is detected by the sensors of the device and transmitted via a Bluetooth connector to a computer where it is displayed on the software programme as a pressure waveform. By completely occluding the brachial artery, 
any local arterial wall changes which may influence the pressure changes are omitted. From the pressure waveform, both PWV and AIx can be calculated. Aortic PWV was calculated as: the aortic length/time delay between two waveforms. The aortic length was calculated from the jugular-symphysis distance using a formula based on patient height provided by the device manufacturer. Alx was calculated as: pulse pressure/(pulse pressure-augmentation pressure) $x$ 100. Brachial Alx was a direct calculation from the waveform and aortic Alx was obtained by the Arteriograph ${ }^{\circledR}$ software's inbuilt generalised transfer function.

Maternal height $(\mathrm{m})$, weight $(\mathrm{kg})$ and brachial blood pressure $(\mathrm{mmHg})$ were obtained prior to the arterial stiffness assessment. Blood pressure (BP) was recorded based on guidance from the British and Irish Hypertension Society. ${ }^{20}$ Patients were seated quietly for 5 minutes prior to measurements being performed. A validated upper arm automatic blood pressure monitor (Microlife $^{\circledR}$, Microlife AG Swiss Corporation, Switzerland) was used with an appropriately sized cuff. The patient's arm was supported at the level of the heart. Mean arterial pressure (MAP) was calculated as $2 x$ diastolic BP + systolic BP /3. Arterial stiffness measurements were recorded from the patient's right arm whilst lying still on a couch in a semi-recumbent position. Participants were asked to refrain from moving or talking during the measurement to allow for a good quality reading. The patient's arm circumference was measured with a tape measure to ensure the correct size cuff was used. Readings with PWV standard deviation less than $0 \mathrm{~m} / \mathrm{s}$ or greater than $1 \mathrm{~m} / \mathrm{s}$ were excluded as these are deemed to represent poor quality readings, as per the manufacturer's advice. A repeat measurement was taken and if the reading was insufficient on three occasions, the procedure was abandoned. Each reading was critically reviewed for quality prior to being included in the study. This included an assessment of the PWV standard deviation, as described above, and of the waveform pattern to ensure there was no artefact. All measurements were performed by trained operators.

The Arteriograph ${ }^{\circledR}$ device was launched in 2005 and has been compared to both invasive techniques and alternative non-invasive techniques. Horvarth et al. 
compared the Arteriograph ${ }^{\circledR}$ measurements of Alx, PWV and central systolic blood pressure $\left(\mathrm{SBP}_{\mathrm{Ao}}\right)$ to invasively-recorded measurements obtained via intra-aortic catheterisation in 16, 55 and 22 patients undergoing routine coronary angiography, respectively. ${ }^{21}$ They reported strong correlation between the measurements $(r=0.94$, $r=0.95$ and $r=0.91$, all $p<0.001$ ) and acceptable agreement in Bland Altman analysis. ${ }^{21}$ Although it has been used extensively in pregnancy, the Arteriograph ${ }^{\circledR}$ has not been validated against invasive methods of arterial stiffness measurement during pregnancy, most likely for ethical and technical reasons.

\section{Statistical Analysis}

Data distribution was assessed using the Shapiro-Wilk test as well as graphical methods. Categorical data were presented as number and percentage, while continuous data were presented as the median and interquartile range (IQR). Statistical analysis was performed using the Chi-square test, Mann-Whitney test and T Test. The Bonferroni correction was applied to control for multiple comparisons. Linear regression was performed to determine which haemodynamic and maternal factors (heart rate, MAP, height, weight, age and gestational age) were associated with PWV and Alx. The differences in Alx and PWV according to ethnicity were tested using Mann-Whitney test or T Test. Multiple regression was performed to adjust for those factors that had a significant association. Linear regression was also used to adjust Alx to a heart rate of $75 \mathrm{bpm}$ as is commonly presented in the literature due to the known inverse relationship between heart rate and Alx. ${ }^{22} \mathrm{~A} \mathrm{p}$ value $<0.05$ was considered statistically significant. Statistical software (SPSS 25.0; SPSS Inc., Chicago, IL) was used to conduct the analysis. 


\section{Results}

Study population

Sixty-nine participants with HDP and SGA, 129 participants with HDP-only and 220 normotensive controls were included in the analysis following the exclusion of 21 women recruited as controls who subsequently gave birth to a SGA neonate. The full demographic and pregnancy characteristics are shown in Table 1 . With the exception of maternal height and adjusted brachial Alx, the data was not normally distributed. There were significant differences in the maternal stature and ethnicity among the study groups. Women in the HDP with SGA group also gave birth to smaller babies at an earlier gestation than in both the other groups (Table 1).

Maternal and pregnancy variables related to PWV and Alx

Univariate linear regression analysis demonstrated that maternal age $(p<0.001)$, weight $(p=0.013)$, height $(p=0.038)$ and heart rate $(p<0.001)$ were significantly associated with brachial and aortic Alx, but gestational age $(p=0.082)$ and MAP $(p=0.407)$ were not. For PWV, maternal weight $(p<0.001)$, height $(p=0.015)$, MAP $(p=0.001)$, heart rate $(p<0.001)$ and gestational age $(p=0.025)$ were significant predictors, whilst maternal age $(p=0.365)$, was not. Multiple regression models of these factors are shown in the supplementary material. There was no difference in PWV or Alx according to ethnicity (all $>0.05$ ), and it was therefore not included as a variable in the models.

Comparison of PWV and Alx among the study groups

Comparisons for crude and adjusted arterial stiffness results are displayed in Table 2 and Figure 1. The HDP with SGA group had significantly (all $p<0.001$ ) higher unadjusted PWV (7.8m/s vs. 6.9m/s), unadjusted brachial Alx (-21.2\% vs. $-63.3 \%)$, unadjusted aortic Alx (26.9\% vs. 5.6\%), aortic augmentation index-75bpm (Alx-75) (25.9\% vs. $0.69 \%)$ and sBP Ao $(137 \mathrm{mmHg}$ vs. $109 \mathrm{mmHg})$ compared to the control group. Heart rate was significantly lower (76 bpm vs. 86bpm, p<0.001). After adjustment for maternal factors, brachial and aortic Alx remained significantly higher 
(both $p<0.001$ ) but there was no difference in PWV $(7.1 \mathrm{~m} / \mathrm{s}$ vs $7.1 \mathrm{~m} / \mathrm{s}, p=0.836)$. The HDP-only group also had significantly (all $p<0.001)$ higher unadjusted PWV $(8.0 \mathrm{~m} / \mathrm{s}$ vs. $6.9 \mathrm{~m} / \mathrm{s})$, unadjusted brachial Alx $(-39.6 \%$ vs. $-63.3 \%)$, unadjusted aortic Alx (17.4\% vs. $5.6 \%)$, aortic Alx-75 (11.7\% vs. $0.69 \%)$ and SBPAo $(129 \mathrm{mmHg}$ vs. 109 $\mathrm{mmHg}$ ) compared to the control group. These results persisted after adjustment for maternal factors, with the exception of adjusted brachial Alx. There was no significant difference in heart rate between the HDP-only group and the control group (83bpm vs. 86bpm, $\mathrm{p}=0.073$ ).

When comparing the HDP with SGA group to the HDP-only group, the HDP with SGA group had significantly higher unadjusted brachial Alx (-21.2\% vs. $-39.6 \%$, $\mathrm{p}<0.001)$, higher unadjusted aortic Alx $(26.9 \%$ vs. $17.4 \%, \mathrm{p}<0.001)$, higher aortic Alx-75 $(25.9 \%$ vs. $11.7 \%)$, higher sBPAo $_{\text {Ao }}(137 \mathrm{mmHg}$ vs. $129 \mathrm{mmHg}, p=0.003)$ and significantly lower heart rate $(76 \mathrm{bpm}$ vs. $83 \mathrm{bpm}, p=0.002)$. There was no significant difference in unadjusted aortic PWV ( $p=0.414)$. After adjustment for maternal factors, brachial and aortic Alx remained significantly higher in the HDP with SGA group. Conversely, adjusted aortic PWV was significantly lower in HDP with SGA group $(7.1 \mathrm{~m} / \mathrm{s}$ vs. $7.7 \mathrm{~m} / \mathrm{s}, \mathrm{p}<0.001)$.

Supplementary analysis excluding patients taking antihypertensive medications at the time of assessment was performed. The differences between the hypertension with SGA group and the hypertension-only groups persisted with the exception of $\mathrm{SBP}_{\mathrm{Ao}}$ and adjusted aortic Alx which were not significantly different (Supplementary table 1). 


\section{Discussion}

Summary of study findings

Women with HDP have significantly higher aortic PWV and Alx compared to normotensive women. Furthermore, in pregnancies complicated by HDP with a SGA neonate, Alx is higher compared to pregnancies complicated by HDP without a SGA neonate. Maternal hemodynamic and anthropometric factors influence both AIx and PWV.

Interpretation of study findings and comparison with the existing literature

The finding of increased arterial stiffness in pregnancies complicated by HDP is in alignment with previous research. ${ }^{14,15,23-25}$ However, there is a paucity of data comparing pregnancies complicated by HDP with SGA neonate and those without. Previous studies have divided preeclampsia into early and late-onset disease and compared these two groups. Franz et al. described increased PWV and Alx using the Arteriograph $^{\circledR}$ device in pregnancies complicated by preeclampsia and the measurements were higher in late-onset disease. ${ }^{14}$ Conversely, Yinon et al. only found a significant difference in Alx compared to controls in the early-onset group. ${ }^{26}$ Others have compared women with gestational hypertension and preeclampsia. Spasojevic et al. reported increased Alx in both their gestational hypertension and preeclampsia groups compared to controls, but the difference was more marked in the preeclampsia group. ${ }^{25}$ The association of SGA neonate in preeclampsia is likely to be a consequence of placental hypoperfusion. This may be secondary to lower cardiac output and higher systemic vascular resistance observed in these pregnancies. $^{27,28}$

The finding of a higher Alx in pregnancies complicated by HDP with SGA compared to pregnancies with HDP-only, but no corresponding difference in PWV is likely to be due to the physiological mechanism behind each measurement. PWV is the speed at which the pulse travels along an arterial segment and is inversely related to arterial distensibility by the Bramwell-Hill formula. Alx is the measure of the magnitude of 
increase in the systolic pressure profile in the artery by pressure waveform reflection. Distensibility is influenced by smooth muscle tone, endothelial activity and the collagen and elastin content of the artery. ${ }^{29-31}$ Whilst both PWV and Alx are influenced by arterial distensibility, Alx is more directly influenced by hemodynamic changes - specifically systemic vascular resistance. ${ }^{30,32,33}$ As the reflected waveform originates mainly in the distal resistance vessels, Alx is proportional to systemic vascular resistance. Higher systemic vascular resistance has been described in pregnancies complicated by preeclampsia with SGA neonate compared to both controls and HDP pregnancies without SGA neonate. ${ }^{34,35}$ Furthermore, PWV has a positive relationship with heart rate, which is significantly lower in pregnancies complicated by HDP with SGA. We have previously described lower heart rate as a contributory factor to lower cardiac output in preeclampsia. As such, it may be more appropriate to consider the unadjusted values for PWV, as a lower heart rate appears to be part of the preeclampsia disease process. Kaihura et al. reported increased PWV but not Alx in patients with preeclampsia following adjustment for confounding factors. ${ }^{24}$ They included all preeclampsia cases together, rather than defining by severity. Therefore, their findings may be in alignment with our finding of increased adjusted PWV in the HDP-only group. The lack of difference in Alx between their preeclampsia and control group may be because their regression calculation for Alx included an adjustment for MAP, a variable we did not find to make a significant contribution.

\section{Clinical and research implications}

There is increasing awareness regarding the link between preeclampsia and cardiovascular disease..$^{2-4}$ The findings of this study support that association, particularly as arterial stiffness is a useful marker of vascular health in the general population. 9,36,37 Small studies of postnatal arterial stiffness have demonstrated higher arterial stiffness following a pregnancy complicated by preeclampsia compared to a healthy pregnancy. ${ }^{26,38}$ It is unclear if these differences pre-date 
pregnancy, or are a consequence of pregnancy itself. Mahendru et al. demonstrated higher postpartum Alx compared to preconception levels in healthy women ${ }^{39}$, but there are currently no preconception comparisons between women who subsequently develop preeclampsia and those that do not.

Recently proposed first trimester screening models for preeclampsia include maternal factors, MAP, serum placental growth factor and uterine artery pulsatility index, with very good detection of early-onset preeclampsia ( $90 \%$ at a $10 \%$ screen positive rate), but modest detection for all preeclampsia (50\% at a $10 \%$ screen positive rate) ${ }^{40} \mathrm{~A}$ previous study demonstrated that the combination of maternal factors, Alx, PWV and central systolic BP had a detection rate for all preeclampsia of $56.9 \%$ at a false positive rate of $10 \% .{ }^{12}$ Given that in this current study, MAP and Alx were independent of each other, the addition of Alx to the screening models may improve performance, particularly with regard to term preeclampsia.

\section{Study limitations and strengths}

The main strengths of this study are that it includes a large cohort of clearly defined hypertensive women and a large control group for comparison. The participants were recruited prospectively, and their pregnancy outcomes were carefully ascertained. Moreover, we have adjusted for the effect of confounding maternal factors and gestational age. One limitation is that we included patients who had been taking antihypertensive medication at the time of assessment. This could have an effect on arterial stiffness. However, the results were unchanged when repeating the analysis excluding these patients. Secondly, some women included in the control group were recruited when attended an ultrasound for suspicion of a small or large for dates fetus. Although we only included those with a normal scan and a normal birthweight at delivery, our control population was not fully unselected, and an element of bias could have been introduced. Finally, although the Arteriograph ${ }^{\circledR}$ device is simple and non-invasive to use, the results that it gives cannot be used interchangeably with those of other devices.

\section{Conclusion}


Pregnancies complicated by HDP have significantly higher PWV and Alx compared to normotensive control pregnancies. The Alx was higher in those pregnancies complicated by HDP with SGA neonate compared to HDP pregnancies with an appropriately grown neonate,

reflecting a progression in severity of arterial stiffness abnormality with a worsening clinical picture. These findings most likely reflect systemic reduced vascular compliance and increased systemic vascular resistance in HDP pregnancies. 


\section{CONFLICT OF INTERESTS}

The authors report no conflicts of interest.

\section{FUNDING}

HP is supported by a grant from the National Institute for Health Research (NIHR) Collaboration for Leadership in Applied Health Research and Care South London at King's College Hospital NHS Foundation Trust. The views expressed are those of the author(s) and not necessarily those of the NHS, the NIHR or the Department of Health. 


\section{References}

1. Jessup M, Abraham WT, Casey DE, Feldman AM, Francis GS, Ganiats TG, Konstam MA, Mancini DM, Rahko PS, Silver MA, Stevenson LW, Yancy CW. 2009 focused update: ACCF/AHA Guidelines for the Diagnosis and Management of Heart Failure in Adults: a report of the American College of Cardiology Foundation/American Heart Association Task Force on Practice Guidelines: developed in collaboration with t. Circulation. 2009;119(14):19772016. doi:10.1161/CIRCULATIONAHA.109.192064.

2. Bellamy L, Casas J-P, Hingorani AD, Williams DJ. Pre-eclampsia and risk of cardiovascular disease and cancer in later life: systematic review and metaanalysis. BMJ. 2007;335(7627):974. doi:10.1136/bmj.39335.385301.BE.

3. Mongraw-Chaffin ML, Cirillo PM, Cohn BA. Preeclampsia and cardiovascular disease death: prospective evidence from the child health and development studies cohort. Hypertens (Dallas, Tex 1979). 2010;56(1):166-171. doi:10.1161/HYPERTENSIONAHA.110.150078.

4. Behrens I, Basit S, Melbye M, Lykke JA, Wohlfahrt J, Bundgaard H, Thilaganathan B, Boyd HA. Risk of post-pregnancy hypertension in women with a history of hypertensive disorders of pregnancy: nationwide cohort study. BMJ. 2017;358:j3078. http://www.ncbi.nlm.nih.gov/pubmed/28701333. Accessed March 8, 2018.

5. Veerbeek JHW, Hermes W, Breimer AY, van Rijn BB, Koenen S V., Mol BW, Franx A, de Groot CJM, Koster MPH. Cardiovascular Disease Risk Factors After Early-Onset Preeclampsia, Late-Onset Preeclampsia, and PregnancyInduced HypertensionNovelty and Significance. Hypertension. 2015;65(3):600606. doi:10.1161/HYPERTENSIONAHA.114.04850.

6. Bonamy A-KE, Parikh NI, Cnattingius S, Ludvigsson JF, Ingelsson E. Birth Characteristics and Subsequent Risks of Maternal Cardiovascular Disease. Circulation. 2011;124(25):2839-2846. 
doi:10.1161/CIRCULATIONAHA.111.034884.

7. Melchiorre K, Sutherland GR, Liberati M, Thilaganathan B. Maternal Cardiovascular Impairment in Pregnancies Complicated by Severe Fetal Growth Restriction. Hypertension. 2012;60(2):437-443. doi:10.1161/HYPERTENSIONAHA.112.194159.

8. Franklin SS, Gustin W, Wong ND, Larson MG, Weber MA, Kannel WB, Levy D. Hemodynamic patterns of age-related changes in blood pressure. The Framingham Heart Study. Circulation. 1997;96(1):308-315. http://www.ncbi.nlm.nih.gov/pubmed/9236450. Accessed October 16, 2018.

9. Sutton-Tyrrell K, Najjar SS, Boudreau RM, Venkitachalam L, Kupelian V, Simonsick EM, Havlik R, Lakatta EG, Spurgeon H, Kritchevsky S, Pahor M, Bauer D, Newman A, Health ABC Study. Elevated Aortic Pulse Wave Velocity, a Marker of Arterial Stiffness, Predicts Cardiovascular Events in WellFunctioning Older Adults. Circulation. 2005;111(25):3384-3390. doi:10.1161/CIRCULATIONAHA.104.483628.

10. Khalil AA, Cooper DJ, Harrington KF. Pulse wave analysis: a preliminary study of a novel technique for the prediction of pre-eclampsia. BJOG. 2009;116(2):268-276; discussion 276-7. doi:10.1111/j.14710528.2008.01906.x.

11. Khalil A, Cowans NJ, Spencer K, Goichman S, Meiri H, Harrington K. Firsttrimester markers for the prediction of pre-eclampsia in women with a-priori high risk. Ultrasound Obstet Gynecol. 2010;35(6):671-679. doi:10.1002/uog.7559.

12. Khalil A, Akolekar R, Syngelaki A, Elkhouli M, Nicolaides KH. Maternal hemodynamics at 11-13 weeks' gestation and risk of pre-eclampsia. Ultrasound Obstet Gynecol. 2012;40(1):28-34. doi:10.1002/uog.11183.

13. Hausvater A, Giannone T, Sandoval Y-HG, Doonan RJ, Antonopoulos CN, Matsoukis IL, Petridou ET, Daskalopoulou SS. The association between 
preeclampsia and arterial stiffness. J Hypertens. 2012;30(1):17-33. doi:10.1097/HJH.0b013e32834e4b0f.

14. Franz MB, Burgmann M, Neubauer A, Zeisler H, Sanani R, Gottsauner-Wolf M, Schiessl B, Andreas M. Augmentation index and pulse wave velocity in normotensive and pre-eclamptic pregnancies. Acta Obstet Gynecol Scand. 2013;92(8):960-966. doi:10.1111/aogs.12145.

15. Namugowa A, Iputo J, Wandabwa J, Meeme A, Buga GAB. Comparison of arterial stiffness in preeclamptic and normotensive pregnant women from a semi-rural region of South Africa. Clin Exp Hypertens. 2017;39(3):277-283. doi:10.1080/10641963.2016.1254227.

16. Khalil A, Jauniaux E, Harrington K. Antihypertensive Therapy and Central Hemodynamics in Women With Hypertensive Disorders in Pregnancy. Obstet Gynecol. 2009;113(3):646-654. doi:10.1097/AOG.0b013e318197c392.

17. Tranquilli AL, Dekker G, Magee L, Roberts J, Sibai BM, Steyn W, Zeeman GG, Brown MA. The classification, diagnosis and management of the hypertensive disorders of pregnancy: A revised statement from the ISSHP. Pregnancy Hypertens An Int J Women's Cardiovasc Heal. 2014;4(2):97-104. doi:10.1016/j.preghy.2014.02.001.

18. Robinson HP, Fleming JE. A critical evaluation of sonar \&quot;crown-rump length\&quot; measurements. Br J Obstet Gynaecol. 1975;82(9):702-710. http://www.ncbi.nlm.nih.gov/pubmed/1182090. Accessed August 5, 2018.

19. Salomon LJ, Alfirevic Z, Da Silva Costa F, Deter RL, Figueras F, Ghi T, Glanc P, Khalil A, Lee W, Napolitano R, Papageorghiou A, Sotiriadis A, Stirnemann J, Toi A, Yeo G. ISUOG Practice Guidelines: ultrasound assessment of fetal biometry and growth. Ultrasound Obstet Gynecol. 2019;53(6):715-723. doi:10.1002/uog.20272.

20. British and Irish Hypertension Society: How to Measure Blood Pressure: Automated Blood Pressure Measurement. https://bihsoc.org/resources/bp- 
measurement/measure-blood-pressure/.

21. Horváth IG, Németh Á, Lenkey Z, Alessandri N, Tufano F, Kis P, Gaszner B, Cziráki A. Invasive validation of a new oscillometric device (Arteriograph) for measuring augmentation index, central blood pressure and aortic pulse wave velocity. J Hypertens. 2010;28(10):2068-2075. doi:10.1097/HJH.0b013e32833c8a1a.

22. Wilkinson IB, MacCallum H, Flint L, Cockcroft JR, Newby DE, Webb DJ. The influence of heart rate on augmentation index and central arterial pressure in humans. J Physiol. 2000;525 Pt 1(Pt 1):263-270. doi:10.1111/J.14697793.2000.T01-1-00263.X.

23. Rönnback M, Lampinen K, Groop P-H, Kaaja R. Pulse Wave Reflection in Currently and Previously Preeclamptic Women. Hypertens Pregnancy. 2005;24(2):171-180. doi:10.1081/PRG-200059871.

24. Kaihura C, Savvidou MD, Anderson JM, McEniery CM, Nicolaides KH. Maternal arterial stiffness in pregnancies affected by preeclampsia. Am J Physiol Circ Physiol. 2009;297(2):H759-H764. doi:10.1152/ajpheart.01106.2008.

25. Spasojevic M, Smith SA, Morris JM, Gallery EDM. Peripheral arterial pulse wave analysis in women with pre-eclampsia and gestational hypertension. BJOG An Int J Obstet Gynaecol. 2005;112(11):1475-1478. doi:10.1111/j.14710528.2005.00701.x.

26. Yinon Y, Kingdom JCP, Odutayo A, Moineddin R, Drewlo S, Lai V, Cherney DZI, Hladunewich MA. Vascular Dysfunction in Women With a History of Preeclampsia and Intrauterine Growth Restriction. Circulation. 2010;122(18):1846-1853. doi:10.1161/CIRCULATIONAHA.110.948455.

27. Perry $\mathrm{H}$, Khalil A, Thilaganathan B. Preeclampsia and the cardiovascular system: An update. Trends Cardiovasc Med. May 2018. doi:10.1016/j.tcm.2018.04.009. 
28. Thilaganathan B, Kalafat E. Cardiovascular System in Preeclampsia and Beyond. Hypertens (Dallas, Tex 1979). 2019;73(3):522-531. doi:10.1161/HYPERTENSIONAHA.118.11191.

29. Bergel $\mathrm{DH}$. The static elastic properties of the arterial wall. J Physiol. 1961;156(3):445. https://www.ncbi.nlm.nih.gov/pmc/articles/PMC1359896/. Accessed April 16, 2019.

30. Mackenzie IS, Wilkinson IB, Cockcroft JR. Assessment of arterial stiffness in clinical practice. QJM. 2002;95(2):67-74. doi:10.1093/qjmed/95.2.67.

31. Van Bortel LM, Duprez D, Starmans-Kool MJ, Safar ME, Giannattasio C, Cockcroft J, Kaiser DR, Thuillez C. Clinical applications of arterial stiffness, Task Force III: recommendations for user procedures. Am J Hypertens. 2002;15(5):445-452. doi:10.1016/S0895-7061(01)02326-3.

32. Glasser S, Arnett DK, McVeigh GE, Finkelstein SM, Bank AJ, Morgan DJ, Cohn JN. Vascular Compliance and Cardiovascular Disease A Risk Factor or a Marker? Am J Hypertens. 1997;10(10):1175-1189. doi:10.1016/S08957061(97)00311-7.

33. Wilenius M, Tikkakoski AJ, Tahvanainen AM, Haring A, Koskela J, Huhtala H, Kähönen M, Kööbi T, Mustonen JT, Pörsti IH. Central wave reflection is associated with peripheral arterial resistance in addition to arterial stiffness in subjects without antihypertensive medication. BMC Cardiovasc Disord. 2016;16(1):131. doi:10.1186/s12872-016-0303-6.

34. Rang S, van Montfrans GA, Wolf $\mathrm{H}$. Serial hemodynamic measurement in normal pregnancy, preeclampsia, and intrauterine growth restriction. $A m \mathrm{~J}$ Obstet Gynecol. 2008;198(5):519.e1-519.e9. doi:10.1016/j.ajog.2007.11.014.

35. Ferrazzi E, Stampalija T, Monasta L, Di Martino D, Vonck S, Gyselaers W. Maternal hemodynamics: a method to classify hypertensive disorders of pregnancy. Am J Obstet Gynecol. 2018;218(1):124.e1-124.e11. doi:10.1016/j.ajog.2017.10.226. 
36. Laurent S, Boutouyrie P, Asmar R, Gautier I, Laloux B, Guize L, Ducimetiere $\mathrm{P}$, Benetos A. Aortic stiffness is an independent predictor of all-cause and cardiovascular mortality in hypertensive patients. Hypertens (Dallas, Tex 1979). 2001;37(5):1236-1241. http://www.ncbi.nlm.nih.gov/pubmed/11358934. Accessed April 10, 2019.

37. Cruickshank K, Riste L, Anderson SG, Wright JS, Dunn G, Gosling RG. Aortic Pulse-Wave Velocity and Its Relationship to Mortality in Diabetes and Glucose Intolerance. Circulation. 2002;106(16):2085-2090.

doi:10.1161/01.CIR.0000033824.02722.F7.

38. Estensen M-E, Remme EW, Grindheim G, Smiseth OA, Segers P, Henriksen T, Aakhus S. Increased Arterial Stiffness in Pre-eclamptic Pregnancy at Term and Early and Late Postpartum: A Combined Echocardiographic and Tonometric Study. Am J Hypertens. 2013;26(4):549-556.

doi:10.1093/ajh/hps067.

39. Mahendru AA, Everett TR, Wilkinson IB, Lees CC, McEniery CM. A longitudinal study of maternal cardiovascular function from preconception to the postpartum period. J Hypertens. 2014;32(4):849-856. doi:10.1097/HJH.0000000000000090.

40. Wright D, Tan MY, O'Gorman N, Poon LC, Syngelaki A, Wright A, Nicolaides $\mathrm{KH}$. Predictive performance of the competing risk model in screening for preeclampsia. Am J Obstet Gynecol. 2019;220(2):199.e1-199.e13. doi:10.1016/j.ajog.2018.11.1087. 


\section{Figure legend}

Figure 1. Box diagrams demonstrating (top to bottom) adjusted Augmentation Index, Heart Rate and Unadjusted Pulse Wave Velocity in the HDP with SGA, the HDP-only and the Control groups. *Indicates $\mathrm{P}<0.05$ compared to the control group. ** indicates $\mathrm{P}<0.05$ compared to the HDP-only group.
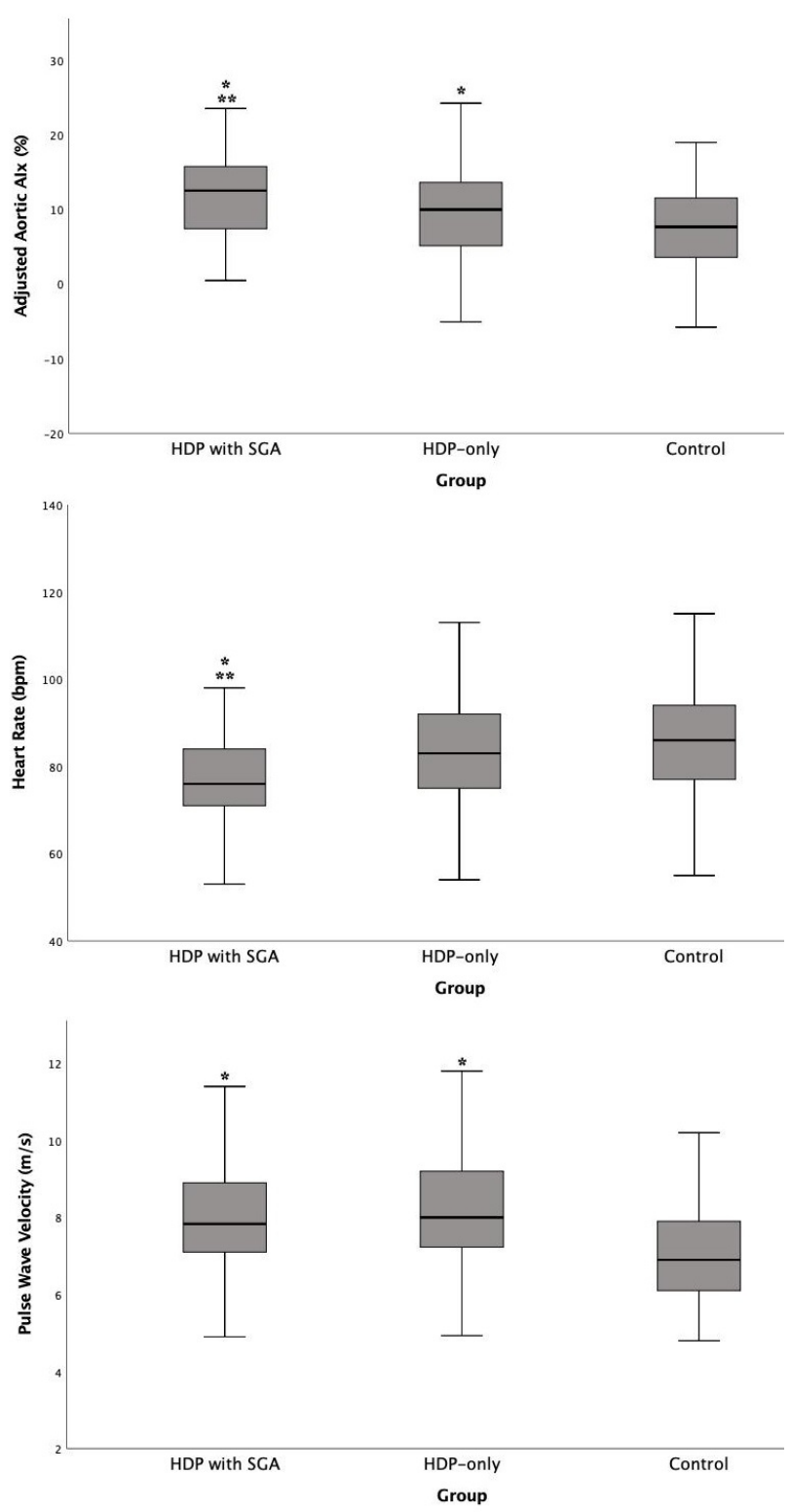
Table 1. Maternal and pregnancy characteristics of women in the hypertension with small for gestational age group, the hypertension-only group and the control group.

\begin{tabular}{|c|c|c|c|c|c|c|}
\hline & \multicolumn{3}{|l|}{ Group } & \multicolumn{3}{|l|}{$P$ value } \\
\hline & $\begin{array}{l}\text { Hypertension } \\
\text { with small for } \\
\text { gestational } \\
\text { age } \\
(n=69)\end{array}$ & $\begin{array}{l}\text { Hypertension-only } \\
(n=129)\end{array}$ & $\begin{array}{l}\text { Control } \\
(n=220)\end{array}$ & $\begin{array}{l}\text { Hypertension } \\
\text { with small } \\
\text { for } \\
\text { gestational } \\
\text { age vs } \\
\text { Control }\end{array}$ & $\begin{array}{l}\text { Hypertension- } \\
\text { only vs } \\
\text { Control }\end{array}$ & $\begin{array}{l}\text { Hypertension with } \\
\text { small for } \\
\text { gestational age vs } \\
\text { Hypertension-only }\end{array}$ \\
\hline $\begin{array}{l}\text { Maternal Age } \\
\text { (years) }\end{array}$ & 31 (28 to 35) & 33 (28 to 36$)$ & 32 (28 to 36$)$ & 0.244 & 0.777 & 0.243 \\
\hline $\begin{array}{l}\text { Gestation at } \\
\text { assessment } \\
\text { (weeks) }\end{array}$ & $\begin{array}{l}33.4(30.0 \text { to } \\
35.3)\end{array}$ & 36.4 (34.4 to 38.1$)$ & $\begin{array}{l}36.0(31.5 \text { to } \\
36.6)\end{array}$ & $<0.001$ & $<0.001$ & $<0.001$ \\
\hline $\begin{array}{l}\text { Maternal height } \\
(\mathrm{cm})\end{array}$ & $\begin{array}{l}161(157 \text { to } \\
165)\end{array}$ & 166 (160 to 171$)$ & $\begin{array}{l}165 \text { (159 to } \\
170)\end{array}$ & 0.005 & 0.150 & $<0.001$ \\
\hline $\begin{array}{l}\text { Maternal weight } \\
\text { at assessment } \\
(\mathrm{kg})\end{array}$ & $\begin{array}{l}78.5(68.2 \text { to } \\
92.7)\end{array}$ & 86.0 (76.3 to 98.5) & $\begin{array}{l}75.6(67.9 \text { to } \\
83.9)\end{array}$ & 0.055 & $<0.001$ & 0.007 \\
\hline $\begin{array}{l}\text { Mean arterial } \\
\text { pressure at } \\
\text { booking }(\mathrm{mmHg})\end{array}$ & 87 (83 to 96) & 93 (88 to 98$)$ & 82 (77 to 89 ) & $<0.001$ & $<0.001$ & 0.003 \\
\hline $\begin{array}{l}\text { Mean arterial } \\
\text { pressure at } \\
\text { assessment }\end{array}$ & $\begin{array}{l}109 \text { (103 to } \\
114)\end{array}$ & 107 (100 to 112 ) & $88(83$ to 94$)$ & $<0.001$ & $<0.001$ & 0.183 \\
\hline
\end{tabular}




\begin{tabular}{|c|c|c|c|c|c|c|}
\hline$(\mathrm{mmHg})$ & & & & & & \\
\hline $\begin{array}{l}\text { Heart Rate } \\
(\mathrm{bpm})\end{array}$ & 76 (71 to 85$)$ & 83 (75 to 92 ) & 86 (77 to 94) & $<0.001$ & 0.073 & 0.002 \\
\hline $\begin{array}{l}\text { Gestation at } \\
\text { delivery (weeks) }\end{array}$ & $\begin{array}{l}35.7(31.9 \text { to } \\
37.9)\end{array}$ & 39.0 (37.6 to 40.0 & $\begin{array}{l}40.0 \text { (38.9 to } \\
40.9)\end{array}$ & $<0.001$ & $<0.001$ & $<0.001$ \\
\hline $\begin{array}{l}\text { Birthweight } \\
\text { centile }\end{array}$ & $\begin{array}{l}2.6(0.77 \text { to } \\
5.5)\end{array}$ & 43.5 (22.5 to 74.8$)$ & $\begin{array}{l}40.7(24.8 \text { to } \\
67.9)\end{array}$ & $<0.001$ & 0.687 & $<0.001$ \\
\hline $\begin{array}{l}\text { Ethnicity, } \mathrm{n}(\%) \\
\text { Caucasian } \\
\text { Afrocarribean } \\
\text { Asian } \\
\text { Mixed/Other }\end{array}$ & $\begin{array}{l}30(43.5) \\
16(23.2) \\
22(31.9) \\
1(1.4)\end{array}$ & $\begin{array}{l}89(69.0) \\
11(8.5) \\
22(17.1) \\
7(5.4)\end{array}$ & $\begin{array}{l}149(67.7) \\
23(10.5) \\
37(16.8) \\
11(5.0)\end{array}$ & $\begin{array}{l}<0.001 \\
0.007 \\
0.007 \\
0.197\end{array}$ & $\begin{array}{l}0.807 \\
0.558 \\
0.955 \\
0.862\end{array}$ & $\begin{array}{l}<0.001 \\
0.004 \\
0.017 \\
0.176\end{array}$ \\
\hline $\begin{array}{l}\text { Antihypertensive } \\
\text { medication, } \\
\mathrm{n}(\%)\end{array}$ & $22(31.9)$ & $24(18.6)$ & $0(0)$ & - & - & 0.035 \\
\hline
\end{tabular}

The values represent median (IQR) or number (\%). Post-hoc Bonferroni correction; significance at P<0.004 
Table 2. Unadjusted and adjusted arterial stiffness values of women in the hypertension with small for gestational age group, the hypertension-only group and the control group.

\begin{tabular}{|c|c|c|c|c|c|c|}
\hline & \multicolumn{3}{|l|}{ Group } & \multicolumn{3}{|l|}{$P$ value } \\
\hline & $\begin{array}{l}\text { Hypertension } \\
\text { with small for } \\
\text { gestational age } \\
(n=69)\end{array}$ & $\begin{array}{l}\text { Hypertension- } \\
\text { only } \\
(n=129)\end{array}$ & $\begin{array}{l}\text { Control } \\
(n=220)\end{array}$ & $\begin{array}{l}\text { Hypertension } \\
\text { with small for } \\
\text { gestational age } \\
\text { vs Control }\end{array}$ & $\begin{array}{l}\text { Hypertension- } \\
\text { only vs Control }\end{array}$ & $\begin{array}{l}\text { Hypertension } \\
\text { with small for } \\
\text { gestational age } \\
\text { vs } \\
\text { Hypertension- } \\
\text { only }\end{array}$ \\
\hline $\begin{array}{l}\text { Central systolic } \\
\text { blood pressure } \\
(\mathrm{mmHg})^{\star}\end{array}$ & 137 (124 to 154$)$ & $\begin{array}{l}129 \text { (119 to } \\
137)\end{array}$ & $\begin{array}{l}106 \text { (98 to } \\
114)\end{array}$ & $<0.001$ & $<0.001$ & 0.003 \\
\hline $\begin{array}{l}\text { Brachial } \\
\text { augmentation } \\
\text { index (\%) }\end{array}$ & $\begin{array}{l}-21.2(-39.5 \text { to }- \\
1.2)\end{array}$ & $\begin{array}{l}-39.6(-53.8 \text { to } \\
-22.7)\end{array}$ & $\begin{array}{l}-63.3(-72.7 \\
\text { to }-50.9)\end{array}$ & $<0.001$ & $<0.001$ & $<0.001$ \\
\hline $\begin{array}{l}\text { Aortic } \\
\text { augmentation } \\
\text { index }(\%)\end{array}$ & $\begin{array}{l}26.9 \text { (17.5 to } \\
36.6)\end{array}$ & $\begin{array}{l}17.4(9.7 \text { to } \\
26.2)\end{array}$ & $\begin{array}{l}5.6(0.85 \text { to } \\
11.5)\end{array}$ & $<0.001$ & $<0.001$ & $<0.001$ \\
\hline $\begin{array}{l}\text { Aortic } \\
\text { augmentation } \\
\text { index-75bpm (\%) }\end{array}$ & $\begin{array}{l}25.9(13.7 \text { to } \\
38.9)\end{array}$ & $\begin{array}{l}11.7(2.0 \text { to } \\
24.8)\end{array}$ & $\begin{array}{l}0.62(-7.1 \text { to } \\
8.0)\end{array}$ & $<0.001$ & $<0.001$ & $<0.001$ \\
\hline $\begin{array}{l}\text { Pulse wave } \\
\text { velocity }(\mathrm{m} / \mathrm{s})\end{array}$ & 7.8 (7.1 to 8.9$)$ & 8.0 (7.2 to 9.3$)$ & $\begin{array}{l}6.9(6.1 \text { to } \\
7.9)\end{array}$ & $<0.001$ & $<0.001$ & 0.414 \\
\hline $\begin{array}{l}\text { Adjusted Brachial } \\
\text { augmentation } \\
\text { index }(\%) \dagger\end{array}$ & $\begin{array}{l}-52.0(-60.0 \text { to }- \\
47.6)\end{array}$ & $\begin{array}{l}-57.4(-65.5 \text { to } \\
-52.0)\end{array}$ & $\begin{array}{l}-60.2(-65.6 \\
\text { to }-54.5)\end{array}$ & $<0.001$ & 0.035 & $<0.001$ \\
\hline Adjusted Aortic & 12.5 (7.4 to 15.7$)$ & 10.0 (5.1 to & 7.6 (3.6 to & $<0.001$ & 0.003 & 0.002 \\
\hline
\end{tabular}




\begin{tabular}{|l|l|l|l|l|l|l|}
\hline $\begin{array}{l}\text { augmentation } \\
\text { index (\%) } \dagger\end{array}$ & & $13.6)$ & $11.5)$ & & \\
\hline $\begin{array}{l}\text { Adjusted Pulse } \\
\text { wave velocity }(\mathrm{m} / \mathrm{s}) \\
\dagger\end{array}$ & $7.1(6.7$ to 7.5$)$ & $7.7(7.1$ to 8.3) & $\begin{array}{l}7.1(6.6 \text { to } \\
7.6)\end{array}$ & 0.836 & $<\mathbf{0 . 0 0 1}$ & $<\mathbf{0 . 0 0 1}$ \\
\hline
\end{tabular}

* Central Systolic blood pressure as measured by the Arteriograph ${ }^{\circledR}$ device. Aortic augmentation index-75bpm= Aortic augmentation index adjusted to a heart rate of $75 \mathrm{bpm}$. $†$ Adjusted Brachial Augmentation Index $=107.887+($ age $\times 0.519)+$ (weight $\times 0.135)-($ height $\times 0.902)-($ heart rate $\times 0.543), R^{2}=0.193, p<0.001$. Adjusted Aortic Augmentation Index $=96.495+($ age $x 0.538)+($ weight $\times 0.149)-$ (height $\times 0.549)-($ heart rate $\times 0.316), R^{2}=0.154, p<0.001$. Adjusted Pulse Wave Velocity $=-4.694+$ (weight $\times 0.027)+($ height $\times 0.028)+($ mean arterial pressure $\times 0.014)+($ heart rate $\times 0.029)+($ gestational age $\times 0.041), R^{2}=0.244$, $\mathrm{p}<0.001$. Post-hoc Bonferroni correction; significance at $\mathrm{P}<0.006$

The values represent median (IQR) 